\title{
KONSEP BERKELANJUTAN PADA KANTOR MILENIAL TERINTEGRASI TRANSPORT HUB DI DUKUH ATAS
}

\author{
Andre Onggara ${ }^{1)}$, Fermanto Lianto ${ }^{2)}$ \\ 1)Program Studi S1 Arsitektur, Fakultas Teknik, Universitas Tarumanagara, Onggaraa@gmail.com) \\ 2) Program Studi S1 Arsitektur, Fakultas Teknik, Universitas Tarumanagara, Fermantol@ft.untar.ac.id
}

\begin{abstract}
Abstrak
Sebagai Urban Interchange, Transport Hub merupakan kunci sukses terjadinya perpindahan dan mobilitas secara berkelanjutan dan mempromosikan penggunaan transportasi publik. Dukuh Atas yang merupakan titik pertemuan beberapa transportasi publik besar seperti: MRT, LRT, KRL Sudirman, dan KRL Bandara menjadi salah satu kawasan berorientasi transit yang sedang direncanakan oleh pemerintah DKI Jakarta dan pihak MRT. Kantor Milenial terintegrasi Transport Hub di Dukuh Atas merupakan bentuk integrasi antara transportasi publik dengan tempat kerja dengan tipologi berbasis aktivitas. Hal ini dipelopori oleh tipe dan perilaku dari milenial yang mendorong pergeseran tipologi dari transport hub dan kantor. Tipologi lama dari kantor dan transport hub sudah tidak cocok untuk generasi milenial. Hal ini mendukung usulan desain transport hub sebagai tempat transit memiliki integrasi ke beberapa transportasi publik dan pribadi dan kantor berbasis aktivitas yang tidak dibatasi dalam cubicle atau ruang individual. Konsep tipologi dari transport hub dan kantor di komposisi ulang dengan metode kualitatif dengan melihat tipologi terdahulunya secara retrospektif dan menganalisis perilaku didalamnya, yang menghasilkan tipologi kantor dan transport hub menjadi satu kesatuan bangunan terintegrasi yang juga terhubung dengan daerah dan fasilitas transportasi publik sekitar. Selain sebagai sarana integrasi transportasi publik sekitar, arsitektur Kantor Milenial terintegrasi Transport Hub menjadi pelopor tempat kerja yang berorientasi transit dan mendorong penghuninya untuk lebih menggunakan transportasi publik guna mengurangi polusi dan kemacetan di kota Jakarta.
\end{abstract}

Kata kunci: Activity-based Office; Milenial; Transport Hub; Urban Interchange

\begin{abstract}
As Urban Interchange of Jakarta, Transport Hub is a key to promote sustainable transportation and mobility and to promote the use of public transportation. Dukuh Atas, as an interchange between major public transportation such as: MRT, LRT, KRL Sudirman, and KRL Bandara has become Transit Oriented Development based on masterplan of Dukuh Atas by Government of Indonesia. Millennial Office integrated with Transport hub is a form of integration between activity-based working space and public transportation. This kind of integration is pioneered by type and behaviour of millennials and it resulting the change of typology. The previous typology of office and transport hub aren't fitted to be used by millennials. This cause the evolution of transport hub as an interchange between many public transportation and private vehicle and also an activity-based office which is separate room or zone based on activity. The Notion of office and transport hub's type are re-composed by retrospectively analyze the typology and behaviour involved in it to be integrated with surrounding place and public transportation. Other than facilitating the interchanging between transportation, the architecture of Millennial Office integrated with Transport Hub at Dukuh Atas became a pioneer of a working place with transport oriented development and to promote the use of public transportation in Jakarta.
\end{abstract}

Keywords: Activity-based Office; Millennial; Transport Hub; Urban Interchange

\section{PENDAHULUAN}

Kota Jakarta dengan banyak pembangunan infrastruktur sarana umum massal (SAUM) memicu perencanaan Kawasan Berorientasi Transit (KBT) yang salah satunya terletak di Dukuh Atas. Dalam perencanaannya, pihak MRT memiliki visi dan misi menjadikan area tersebut 
sebagai gerbang internasional kota Jakarta. Hal ini dikarenakan Dukuh Atas merupakan suatu kawasan di jantung kota Jakarta yang terletak di area bisnis perkotaan dan sarat akan titik simpul berbagai pergerakan warga urban Ibukota melalui Railink, Krl Commuter Jabodetabek, TransJakarta, dan 2 koridor LRT serta MRT.

Dalam perencanaan Kawasan Berorientasi Transit (KBT), terdapat rencana pembangunan transport hub dan kantor yang terletak di jalan kendal (didepan stasiun Sudirman), dalam pengembangannya sebagai sebuah fasilitas publik (transport hub) dengan segala fasilitasnya sebagaimana arahan Gubernur DKI Jakarta ada 29 maret 2019. Transport hub dan kantor sebagai fasilitas publik sekaligus program komersial yang mendukung keberhasilan suatu TOD memiliki kaidah-kaidah yang harus dipertahankan dalam upaya keberhasilan sebuah transport hub untuk mempromosikan penggunaan transportasi publik.

Saat ini Indonesia telah memasuki era Industri 4.0, ditandai serba digitalisasi dan otomasi. Generasi millenial ialah yang berada di usia produktif dan memiliki jumlah terbesar saat ini menjadi golongan dengan signifikansi terbesar yang perlu diperhatikan. Maka dari itu, untuk memastikan agar transport hub dan kantor memenuhi tugasnya, diperlukan pengkajian kembali tipologi transport hub dan kantor yang dipengaruhi perilaku dan nilai kesejamanan.

Dari latar belakang di atas didukung dengan rencana peruntukan lahan pemerintah maka diusulkan proyek ini dengan judul "Kantor Milenial terintegrasi Transport Hub di Dukuh Atas".

\section{KAJIAN LITERATUR}

\section{Milenial}

Milenial (juga dikenal sebagai generasi Y, Gen Y atau Generasi Langgas) adalah kelompok demografi setelah generasi X (Gen-X). Tidak ada batas waktu yang pasti untuk awal dan akhir dari kelompok ini. Para ahli dan peneliti biasanya menggunakan awal 1980-an sebagai awal kelahiran kelompok ini dan pertengahan tahun 1990-an hingga awal 2000-an sebagai akhir kelahiran (Sebastian \& Amran, 2017). Kaum Millennial adalah mereka mereka generasi muda yang terlahir antara tahun 1980an sampai 2000. Kaum Millennial terlahir dimana dunia modern dan teknologi canggih diperkenalkan publik (contoh: gawai). Millennial datang usia dalam waktu dimana industri hiburan mulai terpengaruh oleh internet dan perangkat seluler. selain Milenium yang paling etnis dan ras yang beragam dibandingkan dengan generasi yang lebih tua dari mereka, mereka juga pada kecepatan yang paling berpendidikan. Hingga 2008, 39.6\% dari Millennials antara usia 18 dan 24 yang terdaftar di perguruan tinggi, yang merupakan rekaman Amerika. Bersama dengan menjadi terdidik, generasi muda juga sangat optimis. Seperti yang dinyatakan di atas dalam prospek ekonomi bagian, sekitar 9 dari 10 Pemuda yang merasa seolah-olah mereka memiliki cukup uang atau bahwa mereka akan mencapai tujuan finansial jangka panjang, bahkan selama ekonomi sulit kali, dan mereka lebih optimis tentang masa depan AS Selain itu, generasi muda juga lebih terbuka untuk perubahan dari generasi yang lebih tua. Menurut Pew Research Center, yang melakukan survei pada tahun 2008, generasi muda adalah yang paling mungkin dari setiap generasi untuk mengidentifikasi diri sebagai liberal dan juga lebih mendukung progresif dalam negeri agenda sosial dari generasi yang lebih tua. Akhirnya, generasi muda kurang terang-terangan agama dari generasi yang lebih tua. Sekitar satu dari empat Milenium yang tidak terafiliasi dengan agama apapun, yang jauh lebih dari generasi yang lebih tua ketika mereka masih usia Milenium (Anderson, 2009;NPR, 2008; Gundersen, 2009).

\section{Kantor}

Kantor adalah unit organisasi terdiri atas tempat, staf personel dan operasi ketatausahaan guna membantu pimpinan (Atmosudirjo, 1982, p. 25); balai (gedung, rumah, ruang) tempat mengurus suatu pekerjaan atau juga disebut tempat bekerja (KBBI, 2019);"A room or part of a building in which people work, especially sitting at tables with computers, phone, etc.," (Cambridge Dictionary, 2019). 


\section{Transport Hub}

Selama beberapa dekade ini, transportasi terintegrasi telah menjadi salah satu topik yang terkemuka dan menjadi perbincangan ber bagai kalangan, dalam hal ini berkontribusi dalam pengembahan fasilitas dan pengkajian ulang terhadap definisi jaringan transportasi (Adamos et al.2012). Pada 2013, Komisi eropa meluncurkan 'Urban Mobility Package', di dalamnya terdapat rencana pengembangan transportasi (SUMPS). Konsep yang terkandung dalam SUMPS terdiri dari beberapa kaidah-kaidah transportasi dan mobilitas modern dan berkelanjutan, termasuk integrasi dari segala jenis transportasi. Meskipun Komisi Eropa telah menyampaikan rencana pengembangan urban interchange (Transport Hub) dalam upaya peningkatan penggunaan transportasi publik, nyatanya penggunaan Transportasi Hub tidak menunjukan hasil yang maksimal. Oleh karena itu, membangun pemahaman mengenai faktor utama yang mempengaruhi penggunaan transportasi publik di zaman ini merupakan salah satu hal yang essensial (CRC Press, 2016, p. 4).

Contoh penerapan yang baik untuk bangunan transport hub di Eropa pertama kali dibawakan oleh Group for Urban Interchanges Development and Evaluation (GUIDE). Dalam analisa mereka, transport hub dikatakan sebagai salah satu fitur utama dalam mendukung transportasi publik yang berkesinambungan. Faktanya dalam sejarah menunjukan bahwa pengenalan transport hub meningkatkan penggunaan transportasi publik (Monzon et al.2013; Di Ciomm et al.209; Brons et al.2009). Komisi Eropa sudah mulai berorientasi ke arah pengembangan Transport Hub demi meningkatkan kesadaran masyarakat dalam menggunakan transportasi publik. Kunci dalam peningkatan penggunaan transportasi publik dan pengurangan transportasi privat berkaitan dengan persepsi dan preferensi dalam efisiensi waktu selama perjalanan (Crozet and Joly 2004). Berbagai studi menggunakan pendekatan utility menunjukan bahwa waktu perpindahan dianggap sebagai suatu yang negatif dan sesuatu yang tidak memiliki nilai guna. Lokasi perpindahan jenis moda, dan peningkatan kenyamanan, keselamatan dan keamanan selama penggunaan transportasi publik adalah kunci utama dalam menarik perhatian publik dalam menggunaan transportasi publik. Lebih kepada 'planning more to travel better (i.e. low carbon transport). Oleh karena itu, Direktorat Riset Transportasi mengidentifikasi transport hub sebagai kunci infrastruktur utama untuk mobilitas yang berkelanjutan.

\section{Hukum Bernoulli}

The Bernoulli Effect: ketika cairan mengalir melalui area dengan kecepatan yang meningkat, maka tekanannya akan turun. Efek Bernoulli ini memiliki banyak aplikasi dalam kehidupan nyata (Bernoulli, 1738)

\section{METODE}

\section{Metode Kualitatif}

Metode kualitatif (Sugiyono, 2017) digunakan untuk menemukan tipologi yang cocok digunakan di tapak perancangan melalui presedensi dari kasus-kasus dan literatur yang mengacu pada "CITY-HUBs: Sustainabe dan Efficient Urban Transport Interchanges" dan beberapa literatur lainnya. Konsep type dipilih untuk menghadirkan sebuah arsitektur yang menjawab soal : dialogue between type and behaviour.

\section{Metode Eksperimental}

Metode eksperimental (Cook, 1970) ditujukan dalam tahap perancangan dengan menggunakan kombinasi dari program dan skema aktivitas. Perancangan yang merespon iklim dan cuaca di Indonesia. 


\section{DISKUSI DAN HASIL}

Dengan menjawab soal tipe, perilaku dan kesejamanan pada kantor dan transport hub melalui studi tipe secara retrospektif untuk menghasilkan tipe yang sesuai untuk kaum milenial.

\section{Konsep dan Tema}

Konsep dan tema bangunan diambil sesuai tipe, perilaku dan kesejamanan. Tipe kantor yang digunakan merupakan kantor berbasis aktivitas yang membagi ruang berdasarkan aktivitas(Lihat gambar $3 \mathrm{~s} / \mathrm{d}$ gambar 6). Pembagian ruang berdasarkan aktivitas dapat menghasilkan ruang yang efektif seperti pada tipe kantor "open plan" namun tetap memberikan kenyamanan ruang dengan mengelompokan ruang sesuai aktivitas sehingga diharapkan terciptanya suasana kerja yang cocok sesuai tipe aktivitas. Desain fasad yang mengkombinasikan paduan antara aluminium panel dengan sistem glazing dengan perbandingan tertentu sesuai arah datang sinar matahari menghasilkan produk fasad yang menarik dan mampu mengurangi penggunaan pendingin ruangan dan pencahayaan buatan dalam bangunan (Lihat gambar 7). Penerapan hukum Bernoulli pada bangunan yang direalisasikan melalui void dan lekukan pada bangunan berfungsi untuk mengurangi panas yang diserap oleh bangunan sehingga dapat mengurangi penggunaan pendingin ruangan (Lihat gambar 8).

\section{Hasil Rancangan}

Berikut merupakan hasil rancangan berupa denah, tampak, dan potongan dengan menggunakan konsep berkelanjutan dan menjawab tipe, perilaku, dan kesejamanan. Pada gambar - gambar terlihat pengaturan zona dan sirkulasi kendaraan untuk program transport hub.

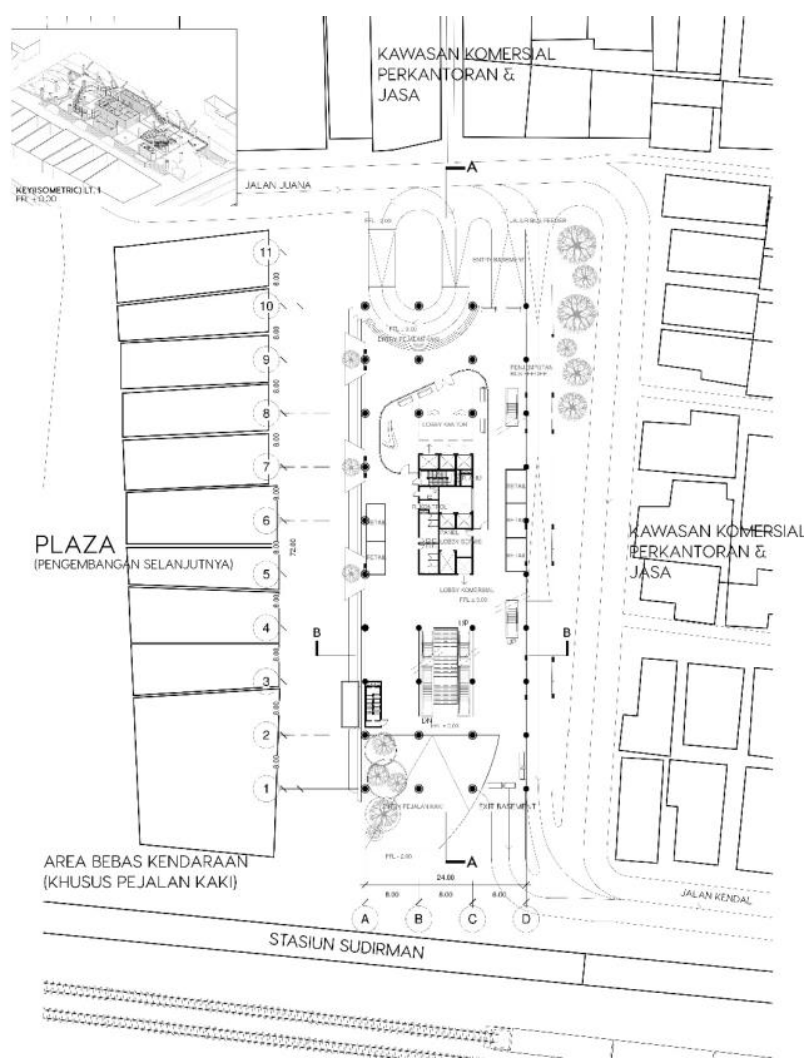

Gambar 1. Denah lantai 1 (area transit dan lobby kantor) Sumber: Penulis, 2019 

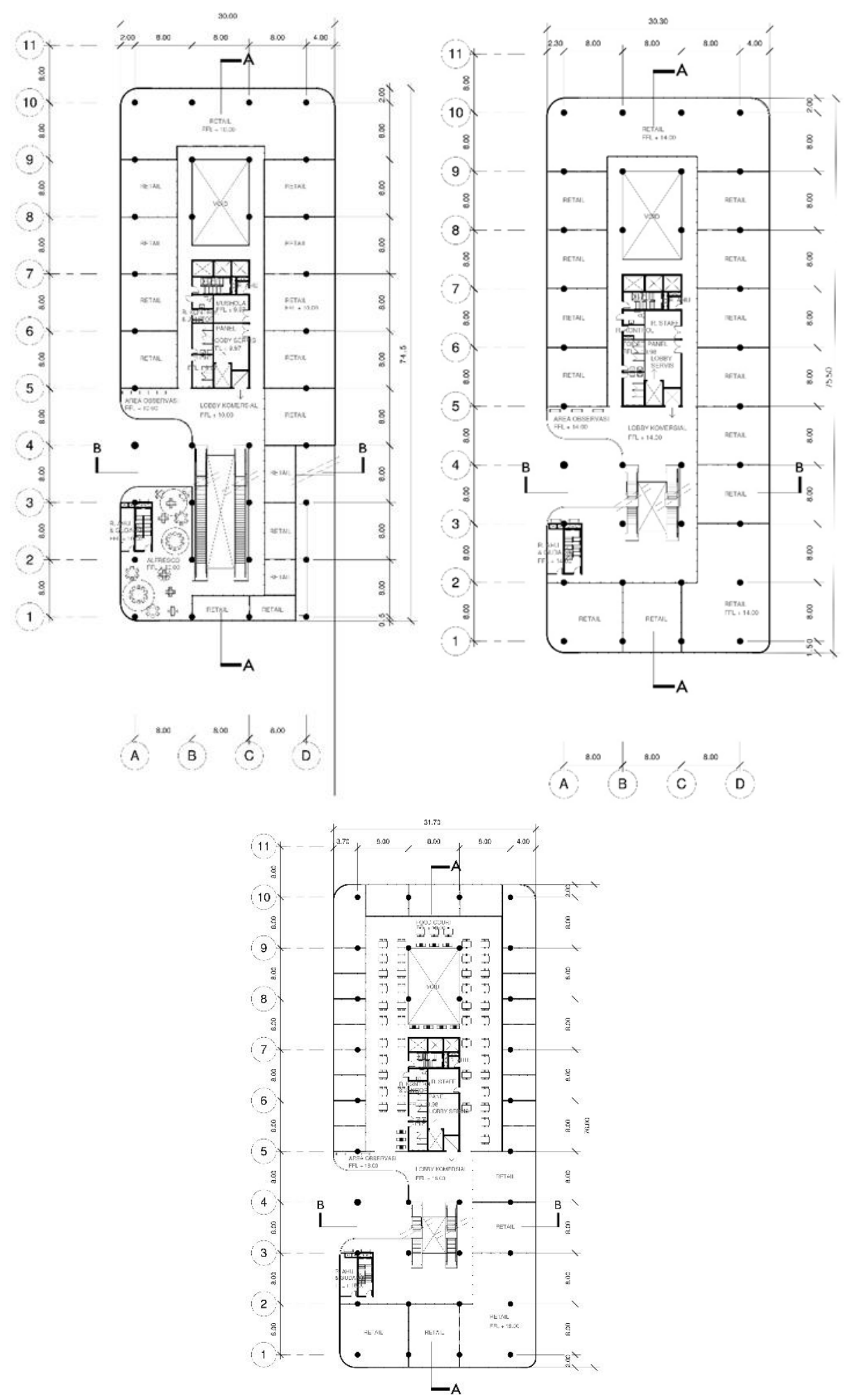

$$
\text { A } 1: 000
$$

Gambar 2. Denah lantai 2,3,4 (Fasilitas Retail) yang memberi tempat transit bagi komuter Sumber : Penulis, 2019 

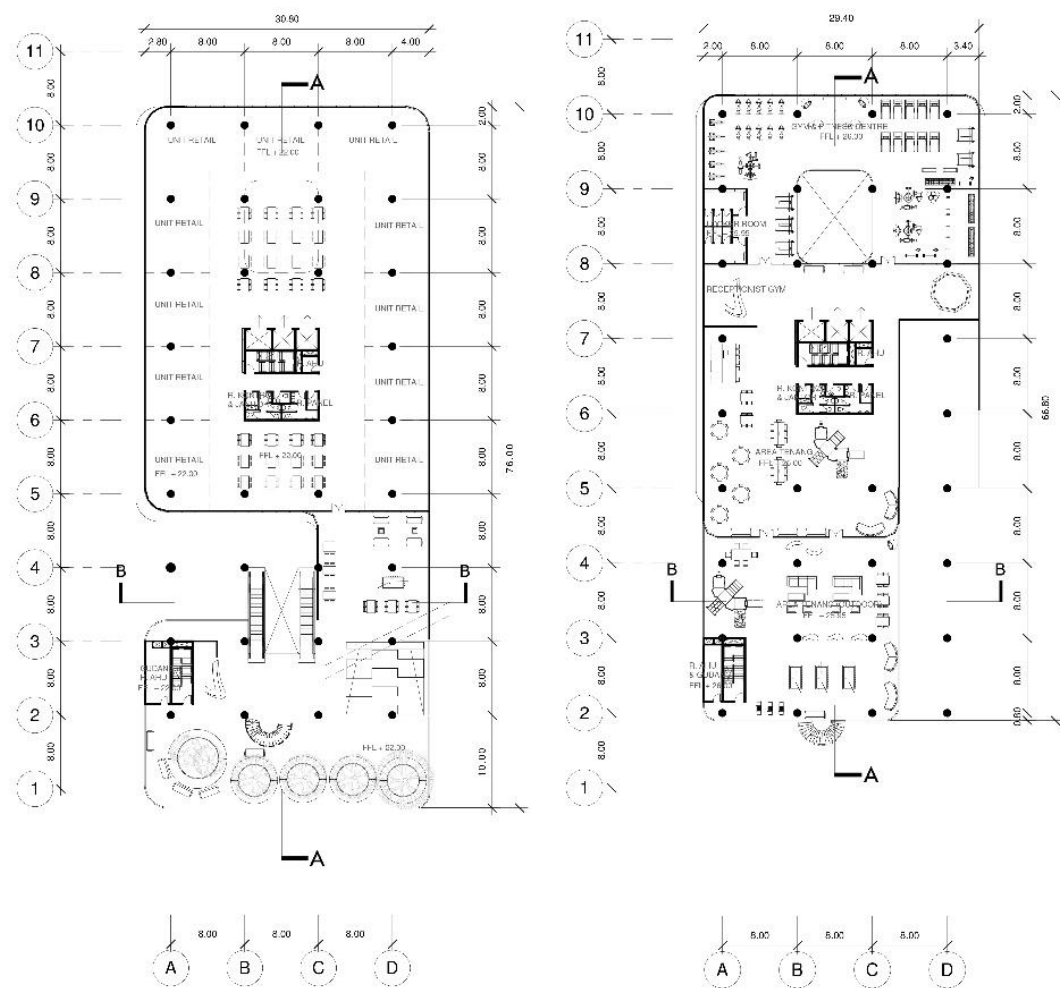

Gambar 3. Denah lantai 5 dan 6 (Zona Tenang) yang menjadi tempat pekerja beristirahat dan merupakan zona semi publik yang menghubungkan tamu dan penghuni kantor Sumber : Penulis, 2019

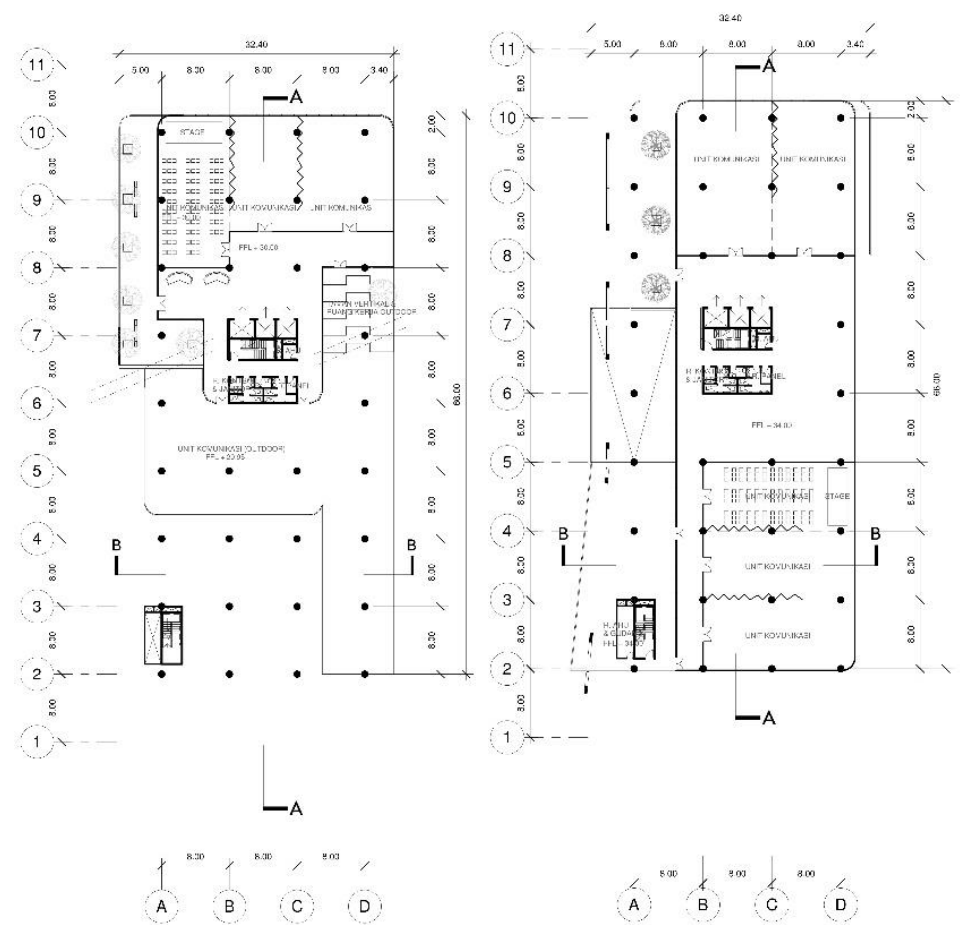

Gambar 4. Denah lantai 7 dan 8 (Zona Komunikasi) yang merupakan area untuk berkomunikasi terdiri dari komunikasi privat, hingga jumlah besar dalam bentuk ruang akustik dan outdoor (Informal)

Sumber: Penulis, 2019 

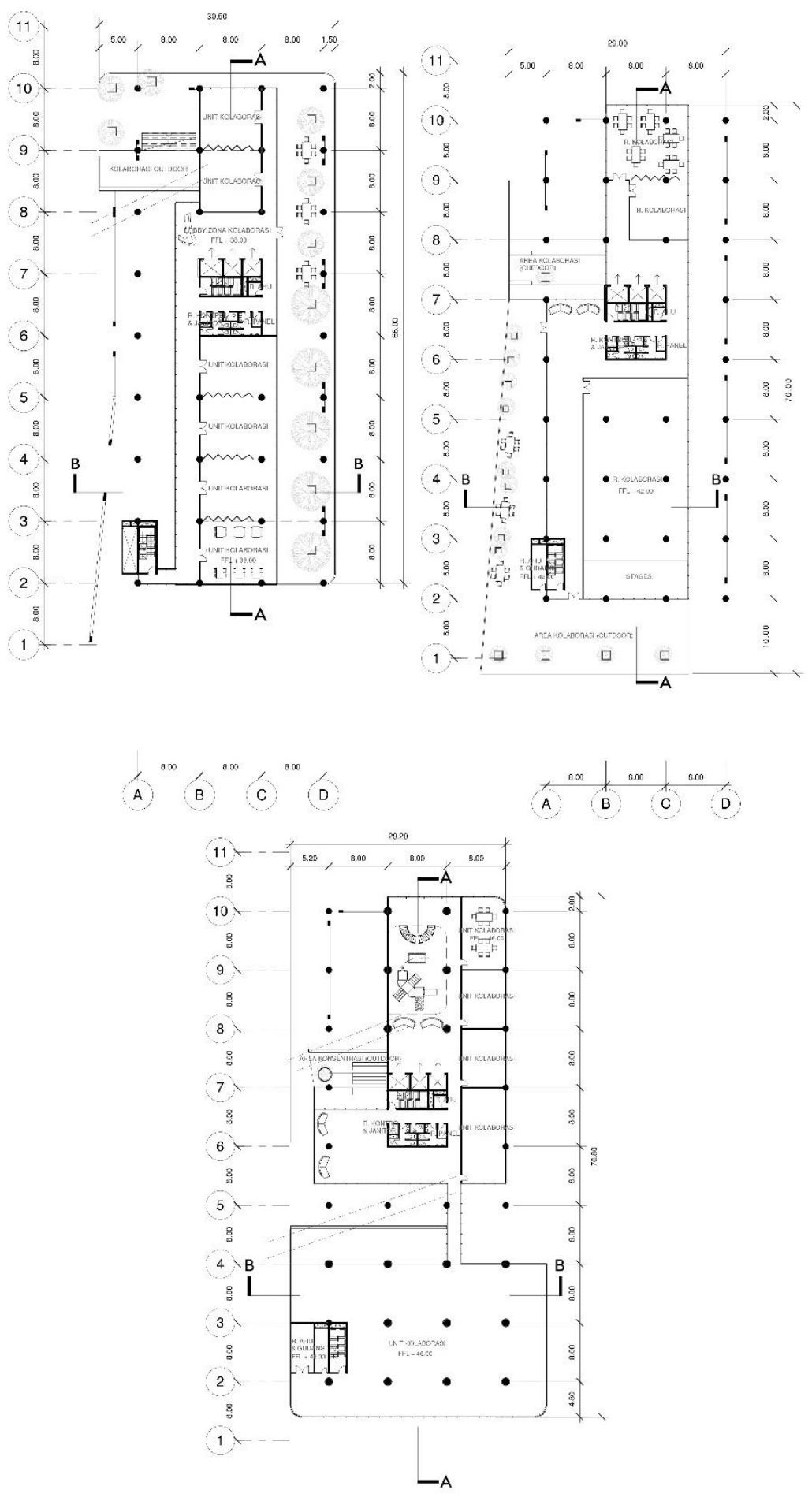

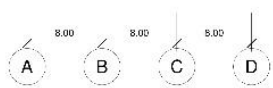

Gambar 5. Denah Lantai 9,10,11 (Zona Kolaborasi) yang menjadi tempat pekerja untuk berkolaborasi secara formal dan informal.

Sumber: Penulis, 2019 

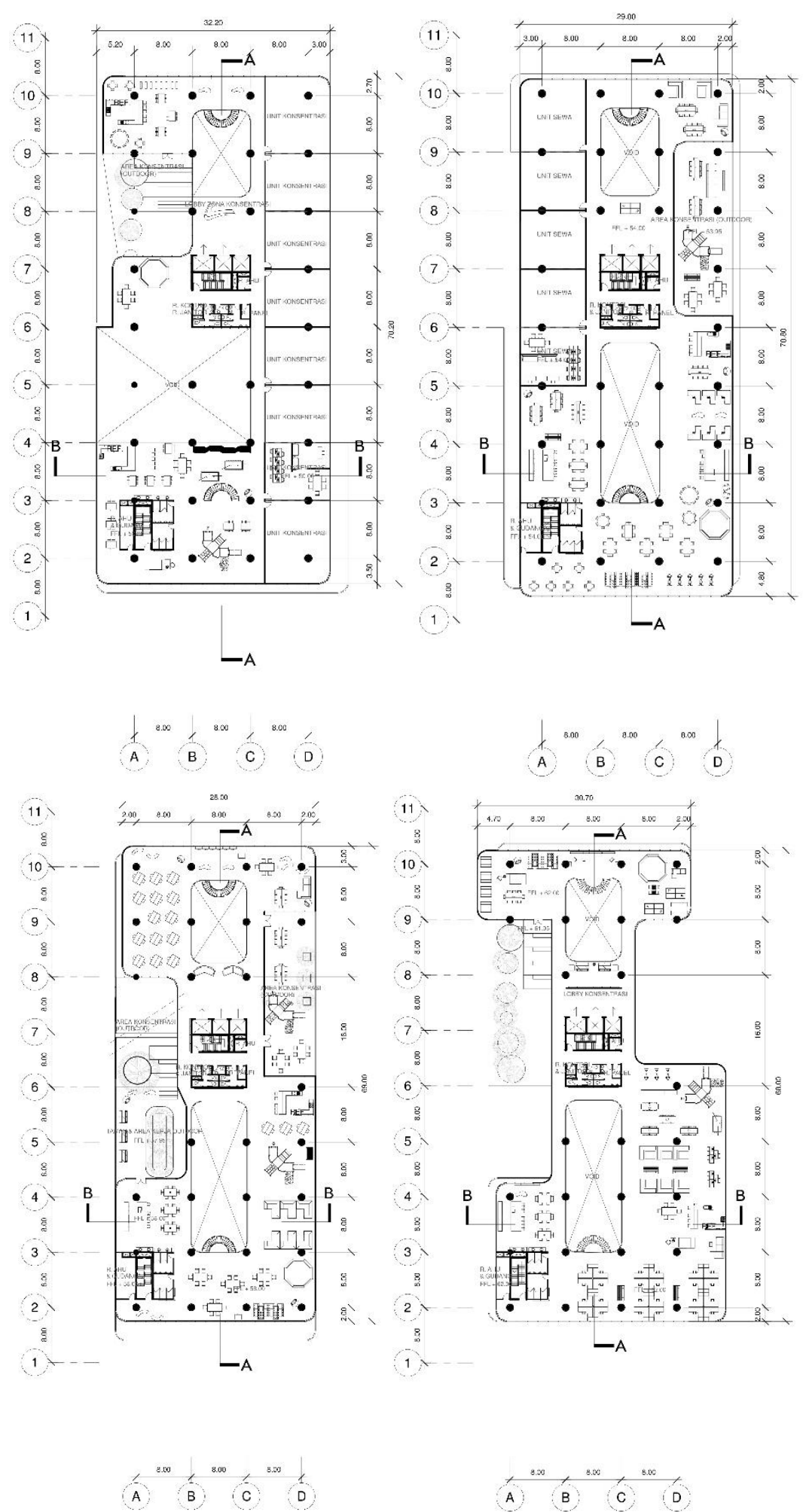

Gambar 6. Denah Lantai 12,13,14,15 (Zona Konsentrasi) yang menjadi tempat pekerja fokus bekerja pada pekerjaan masing-masing dengan ruangan yang kondusif.

Sumber: Penulis, 2019 


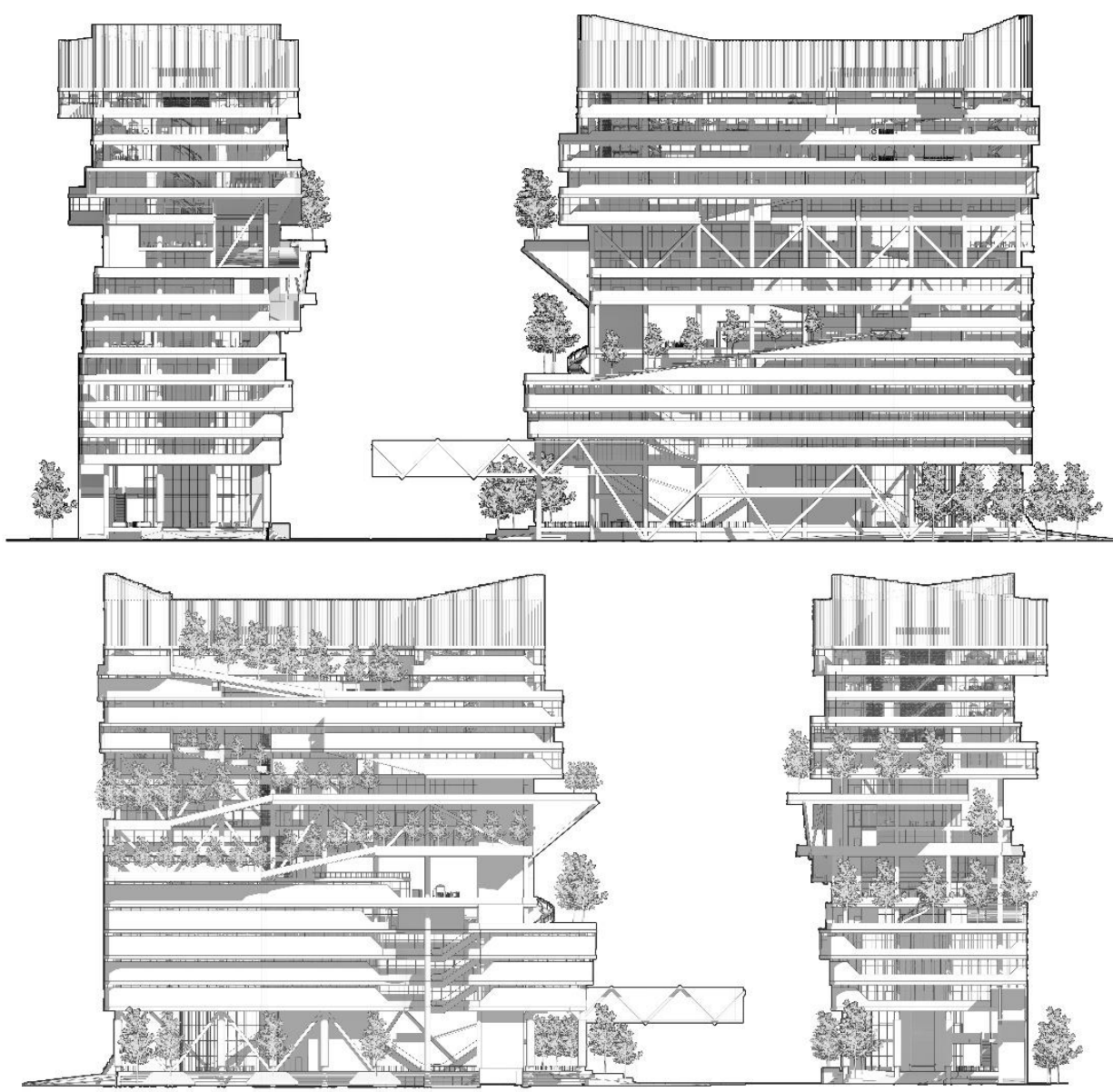

Gambar 7. Konsep fasad terhadap arah datang sinar matahari Sumber : Penulis, 2019

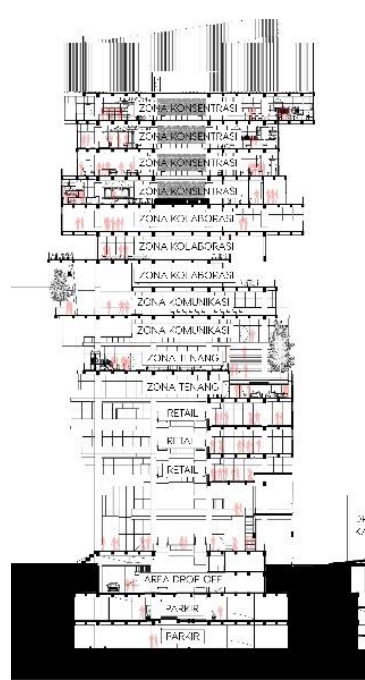

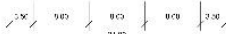

(1)

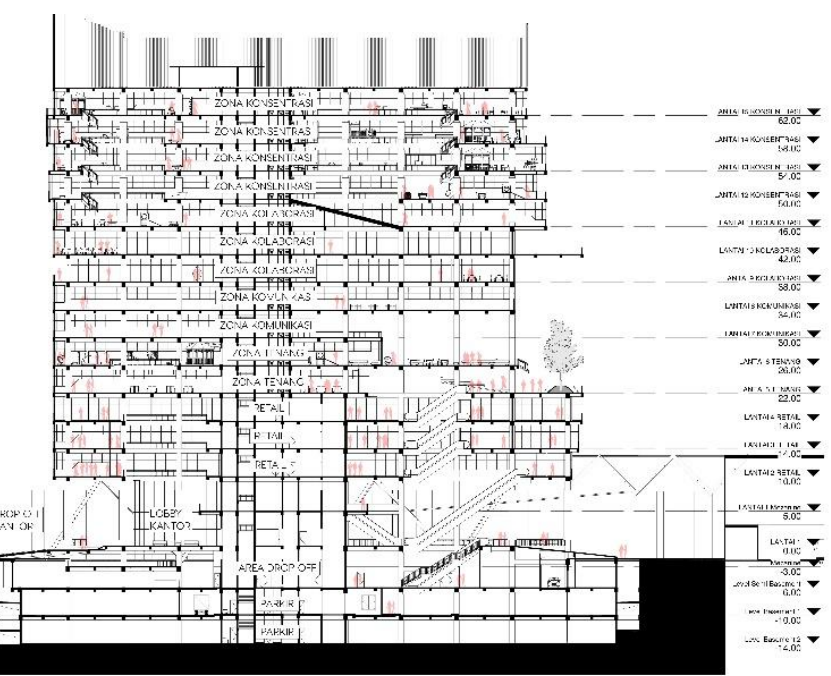

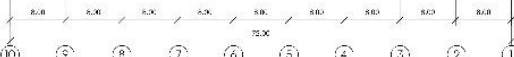

Gambar 8. Penerapan konsep hukum bernoulli pada pengolahan potongan Sumber : Penulis, 2019 


\section{KESIMPULAN DAN SARAN}

Penerapan Hukum Bernoulli dengan memanfaatkan aliran udara melalui void dan bentuk bangunan untuk pengurangan panas bangunan dan kombinasi material kaca dan aluminium panel untuk mengurangi penyerapan panas namun tetap menyediakan pencahayaan alami pada bangunan Kantor Milenial Terintegrasi Transport Hub di Dukuh Atas sangat cocok dalam penerapannya.

\section{REFERENSI}

Anderson, K., (2009). Pop Culture in the Age of Obama. New york: The New York Times.

Atmosudirjo, P., 1982. p. 25.

Bernoulli, D., (1738). Hydrodynamica. s.I.:Daniel Bernoulli.

Cambridge Dictionary, (2019). Cambridge Dictionary. [Online] Available at: https://dictionary.cambridge.org/dictionary/english/office [Accessed 0907 2019].

Cook, P., (1970). Experimental Architecture. s.l.:s.n.

CRC Press, (2016). City-Hubs : Sustainable and Efficient Urban Transport Interchanges. Florida:

Taylor and Francis Group.

Gundersen, E., (2009). The decade in music: Sales slide, pirates, digital rise. s.I.:USA Today.

KBBI, (2019). Kamus Besar Bahasa Indonesia (KBBI). [Online] Available at: https://kbbi.web.id/kantor [Accessed 1807 2019].

NPR, (2008). The Sound of a Generation. s.I.:NPR.

Sebastian, Y. \& Amran, D., (2017). Memahami Generasi Langgas (Millennials). s.I.:SWA.co.id.

Sugiyono, (2017). Metode Penelitian Kuantitatif, Kualitatif, dan R\&D. s.I.:s.n 